\title{
HEROIN-RELATED DEATH - A REVIEW
}

\author{
Burulianova I., D. Radoinova \\ Department of Forensic Medicine, Faculty of Medicine, Medical University - Varna
}

Reviewed by: assoc. prof. N. Negrev

\begin{abstract}
The purpose of this study is to analyse all autopsied cases from 2007 to 2011 year (5 years), died from heroin overdose. Also we made a review of the problem. We investigated 13 cases. In all cases the chemical analysis found morphine, the active component of heroin after hydrolyses. There were in some cases alcohol and benzodiazepines, also traces of marijuana, barbiturates or amphetamines.
\end{abstract}

Key words: heroin overdose cases, chemical analysis, review

Drug abuse is a worldwide problem with numerous manifestations. It is essential for the forensic practitioner to know about the major drugs of dependence and abuse and to be able to recognize the signs of drug abuse on physical examination of either the living or dead.

Drug addiction also refers to serious behavioral problems. It can be said to exist when either of two conditions apply. One is when drug use has become excessive, requiring considerable time and resources and diverting the person from more productive activity. The other is when it has become difficult for the individual to stop using the drug. The impact of these two conditions can vary among different drugs and people. A person who spends the greater part of his day earning money (by stealing, prostitution etc.) to buy drug (for example heroin), locating a source of heroin, is certainly an addict (11).

Opiates, both naturally occurring and synthetic, are very common drugs of abuse. Heroin was introduced to medicine and the public in the early part of the 20th century as a replacement for morphine and codeine. When introduced, one of the claims made for it was that it was non-addictive. While it does have certain therapeutic advantages over morphine and codeine, heroin is much more addictive (8). Morphine and heroin are effective when administered by number of routes, including oral, intramuscular, transmucosal (snorting), subcutaneous and intravenous, and they are effective when inhaled in smoke. Inhaling the smoke from heroin that is burned on a piece of aluminum foil (chasing the dragon), is also a popular way to take heroin without intravenous injection. Both heroin and morphine are metabolized more rapidly after oral than after

\footnotetext{
Address for correspondence:

D. Radoinova,Dept. of Forensic Medicine

Medical University-Varna

Tel. 052/978 783, mob. 0879202927 ,

e-mail:dradoinova@mail.bg
}

other routes of administration, so that relatively large amounts of the drug are necessary to obtain an effect (10). Accidental overdose is the most common cause of death amongst heroin users. Death from heroin overdose is due to depression of respiratory center in the brain. Opiates are central nervous system depressants and heroin causes excitation by lifting cortical inhibitions in a similar manner to alcohol. Opiates soon induce tolerance, so that increasing doses must be used for the same effect. Drugs that gain rapid access to the brain are more likely to be abused than drugs with a slower onset of action.

Heroin is very lipophilic and enters the brain more rapidly than morphine after intravenous administration. The rapid entrance of heroin into the CNS is the main reason that it is the opioid of choice among drug abusers. Once in the brain, heroin is quickly hydrolyzed to monoacetylmorphine and morphine, which are thought to be the active components of heroin (9). Both heroin and morphine can act on opioid receptors that are responsible for the effects of these drugs (8). The signs of opiate toxicity commonly include pinpoint pupils, sweating, warm skin, low blood pressure and slow breathing, which may progress to respiratory arrest if the dosage is high enough. Heroin can also cause sudden death, but the exact mechanism involved in any individual case will probably remain obscure unless admission to hospital and clinical monitoring has occurred. Severe pulmonary oedema is the common autopsy findings and this has probably developed from an acute left ventricular failure due to sudden ventricular dysrhythmia. Death may also occur from poisonous contaminants (strychnine) that have been used accidentally or deliberately to dilute the drugs.

The heroin overdose syndrome consists of abnormal mental status (coma), substantially decreased respiration and miotic pupils (1).

Extensive research has shown the following risk factors for overdose: using the drug intravenously; having a history of heroin dependence; using the drug after a period of non-use or reduced use; not being in treatment for heroin depend- 
ence; concomitant use of depressants, such as alcohol and benzodiazepines, e.g. valium.

It is commonly believed that many overdose deaths occur among young, relatively inexperienced heroin users. However, research has consistently found that most victims of fatal overdose are aged in their late 20 s and early 30 s, who generally have a long history of heroin dependence.

Another finding, revealed by research, is that in a large proportion of fatalities there was a relatively low blood morphine concentrations. This finding conflicts with the widely held view that an overdose is a result of using a quantity of the drug in excess of the person's normal tolerance. In the other hand, there were 20-25 nonfatal cases (around 150 000 cases yearly in EU) on every case of fatal overdose (3). The loss of tolerance that occurs, following termination of heroin use, may vary for different effects of the drug. Users, who reduce their consumption, may be at greater risk of overdose as their tolerance to the respiratory depressant effects may have diminished more rapidly than their tolerance to the psychological effects of the drug.

Concomitant use of other central nervous system depressant drugs, in particular alcohol and benzodiazepines, is known to increase the risk of heroin overdose, both fatal and non-fatal. Heroin is more likely to cause overdose in people who have been drinking alcohol or taking benzodiazepines because these substances can potentiate the respiratory depressant effects of the opiate.

Moreover, research has shown only a moderate correlation between the purity of the street heroin seizures and the numbers of deaths from overdose. Research has also dispelled the notion that overdose fatalities are related to contaminants in heroin.

Table 1. Distribution of the cases

\begin{tabular}{|c|c|c|c|c|c|}
\hline № & Sex & Age & \multicolumn{2}{|r|}{ Drug mg \% } & Alcohol \\
\hline 1 & male & $23(2007)$ & $\begin{array}{l}\text { Morphine } \\
\text { Blood - } 0,15 \mathrm{mg} \% \\
\text { Liver- } 0,10 \mathrm{mg} \%\end{array}$ & Traces of barbiturates and benzodiazepines & Blood - no alcohol \\
\hline 2 & male & $42(2007)$ & $\begin{array}{l}\text { Morphine } \\
\text { Blood - 0,07 mg\% }\end{array}$ & Cocaine in first and second passages & Blood - no alcohol \\
\hline 3 & male & $24(2008)$ & $\begin{array}{l}\text { Morphine } \\
\text { Blood - } 0,08 \mathrm{mg} \%\end{array}$ & Benzodiazepines (diazepam) & Blood - no alcohol \\
\hline 4 & male & $25(2008)$ & $\begin{array}{l}\text { Morphine } \\
\text { Second passages - } 0,08 \mathrm{~m}\end{array}$ & & Blood - no alcohol \\
\hline 5 & male & $25(2008)$ & $\begin{array}{l}\text { Morphine } \\
\text { Blood - 0,08 mg\% }\end{array}$ & Traces of benzodiazepines & Blood - no alcohol \\
\hline 6 & male & $29(2008)$ & $\begin{array}{l}\text { Morphine } \\
\text { Second passages - } 0,06 \mathrm{~m}\end{array}$ & Traces of benzodiazepines & Blood - $0,2 \%$ o \\
\hline 7 & male & 29 (2009) & $\begin{array}{l}\text { Morphine } \\
\text { Blood }-0,07 \mathrm{mg} \%\end{array}$ & Cocaine -more than $300 \mathrm{mg} / \mathrm{ml}$ & Blood - no alcohol \\
\hline 8 & male & $25(2009)$ & $\begin{array}{l}\text { Morphine } \\
\text { Secong passages- } 0,08 \mathrm{mg}^{\mathrm{C}}\end{array}$ & Heroin in the syringe & $\begin{array}{l}\text { Blood - } 0,5 \\
\text { Urine- } 1,3 \% \text { o }\end{array}$ \\
\hline 9 & male & 27 (2009) & $\begin{array}{l}\text { Morphine } \\
\text { First passages }-0,06 \mathrm{mg} \%\end{array}$ & $\begin{array}{l}\text { Heroin in the oral surface and the esophagus } \\
\text { Blood- } 0,04 \mathrm{mg} \%\end{array}$ & Blood 2,2\%o \\
\hline 10 & male & $27(2010)$ & $\begin{array}{l}\text { Morphine } \\
\text { Second passages - } 0,06 \mathrm{~m}\end{array}$ & $\begin{array}{l}\text { Amphetamine } \\
\% \text { Heroin in the syringe }\end{array}$ & Blood $2 \%$ o \\
\hline 11 & male & $32(2010)$ & $\begin{array}{l}\text { Morphine } \\
\text { Blood- } 0,08 \mathrm{mg} \%\end{array}$ & $\begin{array}{l}\text { Methamphetamine } \\
\text { Traces of Marijuana } \\
\text { Traces of benzodiazepines }\end{array}$ & Blood $0,7 \%$ o \\
\hline 12 & male & $38(2010)$ & Morphine $0,06 \mathrm{mg} \%$ & $\begin{array}{l}\text { Methamphetamine } \\
\text { Traces of Marijuana } \\
\text { Traces of benzodiazepines }\end{array}$ & Blood $0,3 \%$ o \\
\hline 13 & male & $28(2011)$ & Morphine $0,08 \mathrm{mg} \%$ & & Blood $0,7 \%$ o \\
\hline
\end{tabular}


In medical examiner's offices, the results of toxicologic testing are correlated with the medical history of the deceased, the autopsy findings, and the circumstances leading up to or surrounding the death, so as to determine whether a drug is a cause of death, a contributing factor, or plays no role.

In many instances, drug levels alone cannot be interpreted. All physicians and toxicologists have had cases where an individual was found to have a fatal level of drug in the blood but was functioning with this level; the drug had nothing to do with the death. This is seen typically in drug abusers who acquire a tolerance to drug levels that would kill an ordinary person, but are normal functioning levels to them. No matter how good one's toxicology laboratory, it cannot function if there is a failure to collect the proper specimens, in adequate quantity, and in the proper containers (6).

Deaths may occur very rapidly, especially with the intravenous use of heroin. A few of the deaths may be due to some personal hypersensitivity to the drug. Some deaths may explain with contamination of the material that was injected rather than to the drug itself. Habituated users are not immune to sudden death. This may be due to hypersensitivity on the basis of previous exposure, but it may also be due to taking an excessive amount of drug. Deaths due to heroin were caused by an allergic reaction to some component used as a cutting agent. In virtually all cases, individuals who die of an overdose of heroin are either under the influence of alcohol or intoxicated at the time of death. Many authors have seen a number of deaths caused by a combination of heroin and cocaine $(4,8)$.

Methadone was introduced as a less dangerous alternative to heroin and was used in substitution treatment for heroin addiction in an effort to reduce dependence. However, it has become a drug of addiction and in some places it is claimed that more deaths occur from methadone than from the drugs it was intended to replace.

The purpose of our study is to analyse all autopsied cases from 2007 to 2011 year (5 years), died from heroin overdose. We investigate 13 cases with acute heroin and mixed intoxication. There were 2 deaths in 2007, 4 in 2008, 3 in 2009, 3 in 2010 and one in 2011. All were boys and young men (the youngest was 23 -years old, the oldest - 42). They were usually found in their houses, in the street, one boy was found in a hotel room and one in the lavatory and there were syringes and needles around the bodies. In all cases the chemical analysis revealed morphine, in part of the cases - traces of barbiturates, benzodiazepines or amphetamine, in 2 cases - cocaine. We have found alcohol in 6 cases, in one (27-years old boy) - the blood level was 2,2\%o. (see Table 1).

Most of the addicts had "needle tracks"- hyperpigmented scars produced by the repeated intravenous injection of the solutions, probably with a dull contaminated needle. Two of them used heroin for the first time after treatment of drug abuse. All the victims had needle punctures in hands, only one - on the right ear. We have found thymus persistent and a large liver and spleen in one case ( 24 years old boy). In all cases there were lung and brain oedema and the sings of asphyxiation or sudden death (rapid death).

\section{DISCUSSION}

In our previous investigations we revealed morphologically abnormal accumulation of blood of the internal organs, lung interstitial haemorrhages, lung oedema, lung emphysema, brain oedema, myocardial fragmentation, aspiration of a gastric contents, thymus persistent, atrophy of the follicles of the spleen, fatty degeneration of the liver (2).

Fatalities, involving only heroin, appear to form a minority of overdose occasions, the presence of other drugs (primarily central nervous system depressants such as alcohol and benzodiazepines), being commonly detected at autopsy (5). In our study, heroin-related death without other drugs or alcohol comprised only one case, chemical analysis except morphine (as active components of heroin) usually revealed depressants (traces of barbiturates, benzodiazepines, marijuana, also cocaine and methamphetamine) (11). The most common combination is heroin with benzodiazepines (1). These data correspond to data for the most European countries (heroin, alcohol and benzodiazepines) (7). This combination can cause death even if the quantity of every substance is small. Diazepam has a long period of release in human body and addicts use this effect to prolong the effect of heroin. Alcohol and heroin have a partial cross tolerance and mutually increasing analgesic effect. The simultaneous administration of heroin, benzodiazepines and/or alcohol increases the side effects and can cause the depression of respiratory center in the brain, coma and circulation disorders. So called "sudden death" in heroin addicts may due to this combination of drugs. This confirm our results 0,06-0,08 $\mathrm{mg} \%$ in most cases are not lethal for morphine the lethal concentration in blood is $0,1-0,5 \mathrm{mg} \%$.

\section{REFERENCES}

1. Radenkova-Saeva, Yu. Acute heroin over-dosage - a clinical and epidemiological study. Health Management, 7, 2007, No 5, 40-46 (in Bulgarian).

2. Radojnova, D., A. Kulova, I. Burulyanova. Morphological alterations in subjects died of heroin over-dose. Annual Proceedings of IMAB, 6, 2000, No 1, 58-60 (in Bulgarian).

3. Bargagli, A. M., Hickman, M, Davoli, M., Perucci, C. A., P. Schifano, et all. Drug-related mortality and its impact on adult mortality in 8 European countries. - European Journal of Public Health, 2006, № 16, 198-202.

4. Baselt, R. C., Disposition of Toxic Drugs and Chemicals in Man. Chemical Toxicology Institute, Foster City CA, 2000, $5^{\text {th }}$ ed.

5. Darke, S., D. Zador. Fatal heroin overdose: a review, addiction. 1996, 91, №12, 1765-72.

6. Di Maio D. and V. Di Maio. Forensic pathology, $2^{\text {nd }}$ ed., Chapter 23: Interpretive Toxicology: 
Drug Abuse and Drug Deaths, 2001, by CRC Press LLC.

7. Evaluating Drug Prevention in the EU: EMCDDA Scientific Monograph Series 1999, No 2.

8. Karch, S. B. The Pathology of Drug Abuse $2^{\text {nd }}$ ed. CRC Press, Boca Raton, FL, 1996.

9. Jaffe, J. H. and W. R. Martin. Opioid analgesics and antagonists. in Goodman and Gilman's The pharmacological Basis of Therapeutics, $8^{\text {th }}$ ed. Elmsfor, NY: Pergamon, 1990, 522.

10. Warner-Smith, M., S. Darke, M. Lynskey and W. Hall: Heroin overdose: causes and consequences, 2001, Addiction 96:1113.

11. Winger, G., J. Woods, F. Hofmann. A handbook on drug and alcohol abuse - The biomedical aspects, $4^{\text {th }}$ ed. Oxford university press, 2004. 